Images du travail, travail des images

\title{
Je ne ferai plus jamais cette image
}

Laurent Kaczor

\section{(2) OpenEdition}

Journals

Édition électronique

URL : http://journals.openedition.org/itti/1142

DOI : 10.4000/itti. 1142

\section{Éditeur}

Université de Poitiers

\section{Référence électronique}

Laurent Kaczor, "Je ne ferai plus jamais cette image », Images du travail, travail des images [En ligne],

3 | 2017, mis en ligne le 01 février 2017, consulté le 14 avril 2021. URL : http://

journals.openedition.org/itti/1142 ; DOI : https://doi.org/10.4000/itti.1142

Ce document a été généré automatiquement le 14 avril 2021.

Images du travail, travail des images 


\title{
Je ne ferai plus jamais cette image
}

\author{
Laurent Kaczor
}

Image 1

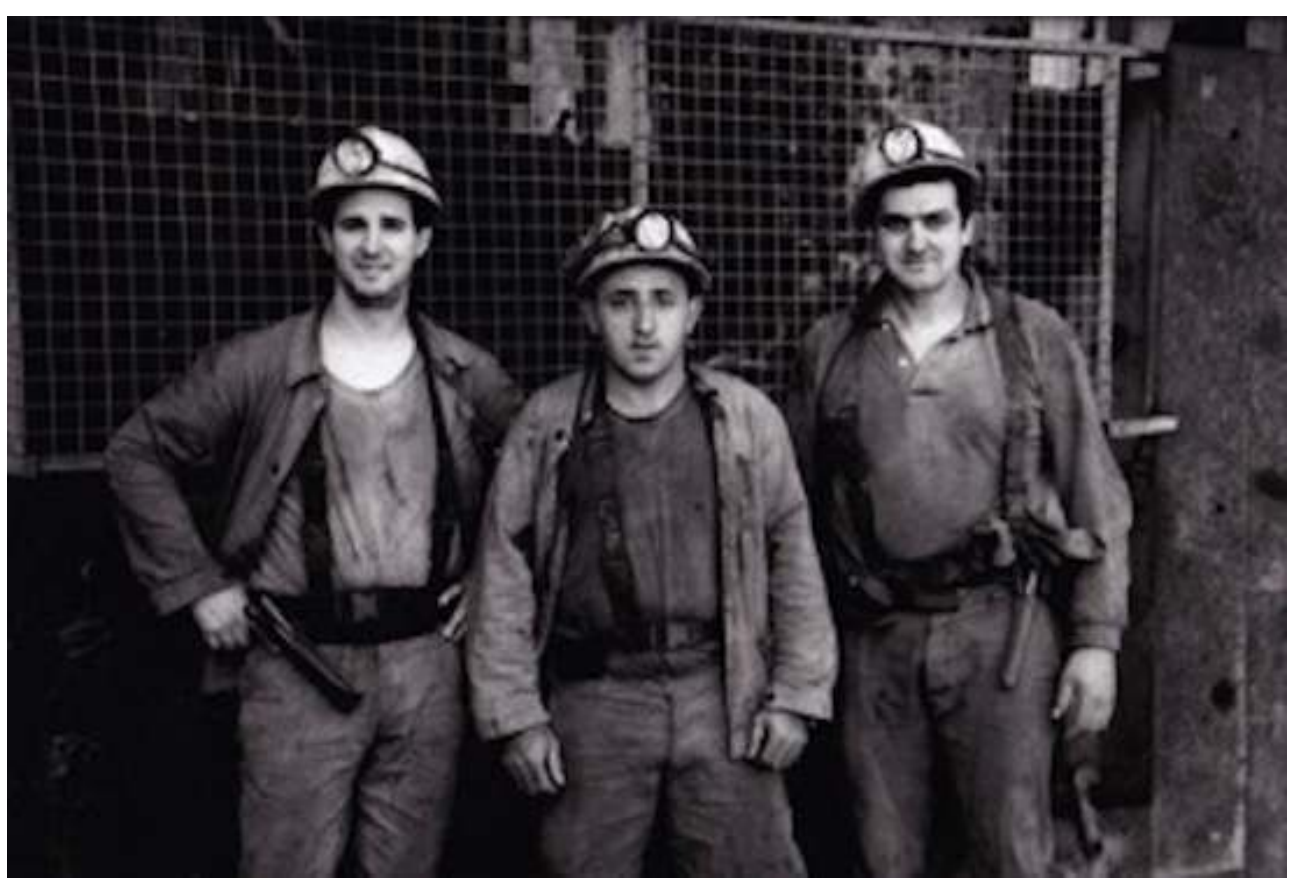

1 Jeune étudiant, déjà intéressé par l'image, j'habitais alors Gardanne, petite ville du sud de la France, dont la particularité était de posséder un des derniers puits de mine alors en activité de l'Hexagone. Cette ville est en outre cernée à l'ouest par une usine d'alumine, qui donne aux murs des maisons les plus proches une teinte rouge et poussiéreuse caractéristique, et au nord par une centrale thermique dont les hautes cheminées sont visibles à des kilomètres à la ronde. Projecteurs, tuyaux, rails, fumerolles et bâtiments de briques et de tôles ont été mon horizon visuel en cette période où j'aspirais à devenir photographe. J'avais obtenu l'autorisation de photographier les installations de surfaces de la mine, mais pas, à mon grand regret, celle de descendre au fond ; pourtant, aujourd'hui, je me dis que ce que j'aurais pu faire 
sous terre, n'aurait sans doute pas la même charge émotionnelle que cette simple image, faite un peu à la va-vite, un peu pour faire plaisir à ces gars qui, fiers de leur travail, voulaient juste poser, comme ça, avec leurs camarades.

2 J'y vois des cow-boys, dans cette attitude à la fois raide et nonchalante, cette manière de se figer comme au temps où l'exposition d'une surface sensible était si lente, qu'il fallait s'empêcher de bouger pour ne pas être flou sur la photo; j'y vois cette même figure sale, burinée par la poussière des plaines pour les uns, par celle du fond pour les autres, j'y vois un monde disparu, avalé par la modernité et la mondialisation - la mine a fermé en 2003, plus rentable en regard du prix du charbon importé de Pologne...

3 J'avais des rêves, devenir reporter-photographe, j'avais un boîtier argentique, une pellicule noir et blanc, j'avais 20 ans. Cette image d'une fin, a aussi été celle d'un début, celle de ma première publication. Je ne ferai plus jamais cette image.

\section{AUTEUR}

\section{LAURENT KACZOR}

Né en France, à Marseille, en 1973, j'ai choisi la photographie, après des études de lettres modernes. J'ai travaillé pour des compagnies théâtrales, réalisé des books de comédiens, et signé mes premiers reportages pour la presse magazine. En 1999, j'ai fondé, avec d'autres, le collectif Synchro-X au sein duquel j'ai produit le livre 17 - Police, plongée dans le quotidien des patrouilles de police-secours dans différents départements français. Durant 5 ans responsable su service photo de Colombes, en région parisienne, j'avais pour mission de fournir à la ville des photos de toutes sortes, ainsi que de gérer une équipe de photographes vacataires. J'avais la responsabilité du fonds photo et de l'archivage. Redevenu photographe indépendant et installé à Lausanne, en Suisse, je collabore avec l'office de tourisme de la ville. J'ai également illustré le guide de tourisme Un grand week-end à Lausanne, sorti en avril 2016 aux éditions Hachette. 